\title{
The Responses of Casing Pipe of Oil-Well Induced by the Swelling of Rocks
}

\author{
Zhang Gende $^{1}$ Lu Xiaobing ${ }^{1}$ Wang Shuyun ${ }^{1}$
}

\begin{abstract}
The responses of casing pipe of oil-well induced by the swelling of rocks are investigated by numerical simulation. It is shown that the swelling of rock may cause severe permanent plastic strain of the steel casing pipe. The displacement of the pipe without a lining is $58 \%$ larger than that with a lining under the same volume swelling condition. A lining may decrease the pressure of the casing pipe caused by the dilation rock. There exists necking phenomenon. The necking of the pipe with a cement lining is larger than that without the cement lining.

Keywords: Casing pipe, oil-well, swelling rock, lining.
\end{abstract}

\section{Introduction}

It is important to study the responses of casing pipe of oil-well induced by the swelling of rock, either theoretically or practically in the oil exploitation. The volume increase of swelling rocks may cause a large pressure on the structure in the rock such as a casing pipe and may cause the damage to the structure. The swelling of rocks is particularly pronounced in rocks containing phyllosilicates because of the easiness with which these minerals hydrate (Wolfqanq et al, 1996). It is thus of geological and geotechnical relevance in shales, clay-rich soils and zeolitized tuffs. By three types of laboratory test: constant stress (creep) test, constant strain-test, and quasi-static, true-triaxial strength test, Samberek et al(1993) showed that the stress conditions are separated into those that produce dilatancy and that produce constant volume flow. Molenaar et al(1998) found that the main operational parameters controlling borehole stability in drilling shales are the density and the chemical composition of the drilling fluid. The density of the drilling fluid provides support of the borehole wall, while the chemical composition of the drilling fluid can be adopted to reduce the infiltration rate and to maintain hole stability for prolonged exposure time of the drilling fluid to the shale.

${ }^{1}$ Institute of Mechanics, Chinese Academy of Sciences, 100080, Beijing, Email: xblu@imech.ac.cn 
In the present paper, we will analyze the responses of the casing pipe in the swelling rock by numerical simulation.

\section{The constitutive relation of swelling rocks}

The classical one dimensional constitutive relation of the swelling rock is as follows which is obtained by using a general consolidation apparatus (Cheng et al, 1987).

$$
\varepsilon=K\left(1-\frac{\log \sigma}{\log \sigma_{0}}\right)
$$

in which $\varepsilon$ is the axial swelling strain, $\sigma$ is the maximum swelling stress, $\sigma_{0}$ is the swelling stress, $K$ is the axial swelling strain when $\sigma=0.1 M P a$.

Einstern(1989), Wittke et al(1979), and Qing et al(1995) presented a threedimensional swelling constitutive relation. Two assumptions are that the swelling strain is caused by the changes of the first invariant and that the sided swelling stresses are in agreement with the following relation:

$$
\sigma_{x}=\sigma_{y}=\frac{v}{1-v} \sigma_{z}
$$

in which $\sigma_{x}, \sigma_{y}$ are the sided swelling stresses.

Under these two assumptions, Einstern (1989) presented a three-dimensional swelling constitutive relation:

$$
\varepsilon_{v}=K\left(1-\frac{\log \left(\sigma_{v} \frac{1-v}{1+v}\right)}{\log \left(\sigma_{v \max } \frac{1-v}{1+v}\right)}\right)
$$

in which $\sigma_{v \max }$ is the maximum swelling volume stress, $v$ is the Poisson's ratio.

The numerical analysis of the interaction between the swelling rock and the casing pipes of oil-well.

There often exist swelling rocks in the terrane in oil field. Casing pipes of oil-well might be damaged if the terrane swells after sucking water. In order to investigate the responses of casing pipes under the swelling pressure, we carry out numerical analysis using finite element method as a plane strain problem and a three-dimensional axisymmetrical problem, respectively. Because of the assumption of isotropic swelling train and the symmetry of structures, this problem may be taken as axisymmetrical. For the convenience and simplification of computation, the responses in radial direction of the pipe are computed as a plane strain problem, while the responses in axial direction of the pipe are computed as a three-dimensional axisymmetrical problem. In the computation of three-dimensional axisymmetrical condition, 1/4 of all 
zone is adopted. The responses of the pipe with and without a cement lining are investigated.

In the analysis, some assumptions are made as follows: 1 the adjoining rock and swelling strains is uniform and isotropic; 2 the adjoining rock and the casing pipe are both elastic-plastic; 3 Eq. (4) is adopted as the constitutive relation of rock; 4 the swelling volume strain is small.

The constitutive relation adopted in this paper is added in the software ABAQUS first and then the computation is processed under three-dimensional axisymmetrical, or plane strain conditions. The mesh under plane strain condition (PSC) and threedimensional axisymmetrical condition (TAC) are shown in Fig.1 and Fig.2 respectively, which define the overall geometry of the finite-element model. A thin layer of continuum elements was used in the region of the rock or the cement lining and the swelling rock interface. The PSC and TAC are used to simplify the analysis and to obtain the stresses and strains in the axial and radial directions of the casing pipe. The parameters adopted in the computation are from literature (The Petroleum Geology Exploitation of Dagang Petroleum Management Bureau ,1999).

First, the stresses computed under self-gravity are taken as the initial earth stress. The upper side is free while the other boundaries are fixed normally. The adjoining rock and the pipe are taken as elastoplastic (Wittke et al, 1979)。The parameters in Eq.(4) are $\mu=0.3, \rho=2700 \mathrm{~kg} / \mathrm{m}^{3}, \sigma_{v \max }=0.21 \mathrm{MPa}$.

The radial displacement distribution of casing pipe with a cement lining is shown in Fig. 3. The displacement of pipe without a cement lining is shown in Fig.4. It is shown that the displacement with a cement lining is $58 \%$ larger than that without the cement lining under the same volume swelling condition. The maximum displacement in the radial direction is located at the interface of cement lining and the swelling rock when there exists a cement lining. While without a cement lining, it is located at the interface of the cement lining and the casing pipe. Therefore, a lining may decrease the pressure of dilation rock on the casing pipe.

These results are in agreement with that of Erans and Harriman (1972). Their results showed that the maximum displacement in the radial direction is located at the interface of the cement lining and the swelling rock. The lining makes the pressure that the casing pipe may bear increase $23 \%$.

Fig.5 and Fig. 6 give the distribution of radial stresses of the pipe with or without a cement lining. The maximum displacement in the radial direction is located at the interface of the cement lining and the swelling rock either with or without a lining. It is shown that the swelling rock may cause a large pressure on the casing pipe after swelling and make the steel casing pipe to produce severe permanent plastic strain.

Figs. 7 and 8 give the distributions of radial displacements in the axial direction of the casing pipe computed under three-dimensional axisymmetrical condition. There exists necking phenomenon either with or without a cement lining. The necking with a cement lining is larger $(0.42 \mathrm{~mm})$ than that without a cement lining $(0.27 \mathrm{~mm})$. Fig. 9 shows the necking phenomena. 


\section{Conclusions}

It is shown that the swelling rock may cause a large pressure and severe permanent plastic strain of the casing pipes after sucking water. The displacement of a pipe without a lining is $58 \%$ larger than that with a lining under the same volume swelling condition. The maximum displacement in the radial direction is located at the interface of the cement lining and the swelling rock when the pipe is with a cement lining. While without a cement lining, it is located at the interface of the cement lining and the casing pipe. Therefore, a lining may decrease the pressure of the casing pipe caused by the dilation of rock. There exists necking phenomenon. The necking with a cement lining is larger than that without the cement lining.

\section{ACKNOWLEDGEMENTS}

This program is supported by the National Natural Science Foundation-Key Yougth Foundation( No. 40025103) and National Natural Science Foundation( No. 10202024).

\section{References}

Cheng Zhongji, Wen xuanmei (1987). "Swelling rock and the stability of tunnel." Rock Mech. And Engrg., 9(5), 32-41, ( in Chinese).

Einstein, H. H. (1989). "Suggested method for laboratory testing of arginaceous swelling rock." Int. J., Rock Mech. Min. Sci., 26(5), 415-426.

Evans, G. W., Harriman, D. W. (1972). "Laboratory tests on collapse resistance of cemented casing." $47^{\text {th }}$ Annual Meeting of the Sciety of Petroleum Engineers of Aime. San Antomio Texas,115-118.

Molenaar M. M., Huyghe, J. M., Van Den Bogert, P. A. J. (1998). "Constitutive model for swelling shales." SPE/International Society of Rock Mechanics in Petroleum Engineering Conference, 2, SPE/ISRM 47332, Trondheim, Norway, 127132.

Qing Y., Guohua L., Shunchuan W. (1995). "The research of 3-D swelling constitutive relation of swelling rock." Chinese J. Rock. Mech. Engrg., 14(1), 33-38. (in Chinese)

Samberek, Leo L. Van, Ratigan, Joe L., Frank H. D. (1993). "Dilatancy of rock salt in laboratory tests." International Journal of Rock Mechanics and Mining Sciences \& Geomechanics Abstracts, 30(7), 735-738. 
The Petroleum Geology Exploitation of Dagang Petroleum Management Bureau (1999). "The deformation and damage analysis of the casing pipes in Gangxi exploitation area." Technical Report.

Wolfqanq, H. K, Wong, S. W. (1996). "Hydration swelling of water-absorbing rocks: A constitutive model." International Journal for Numerical and Analytical Methods in Geomechanics, 20(6), 403-430.

Wittke, W., Pierau B. (1979). "Foundations for the design and construction of tunnel in swelling rock." Proc. the $4^{\text {th }}$ Int. Cong. On Rock Mech., Montreux, Switerland, (2), 219-229.

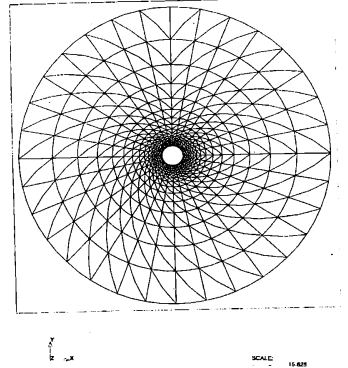

Fig. 1 The mesh under plane strain condition

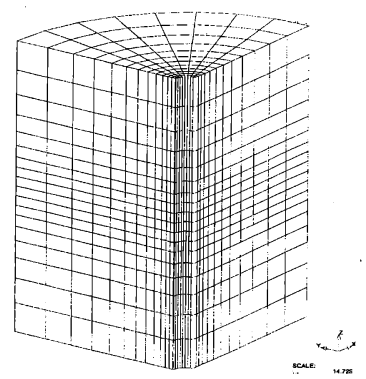

Fig. 2The mesh under three-dimensional axisymmetrical condition

(Because of the assumption of isotropic swelling train and the symmetry of structures, this problem may be taken as axisymmetrical. In the computation, 1/4 of all zone is adopted. )

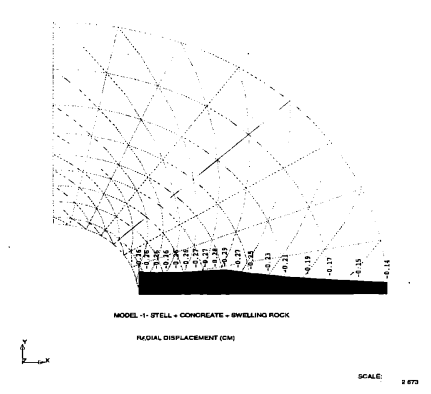

Fig.3 The displacement distribution of the rock in radial direction under swelling pressure( with cement lining)

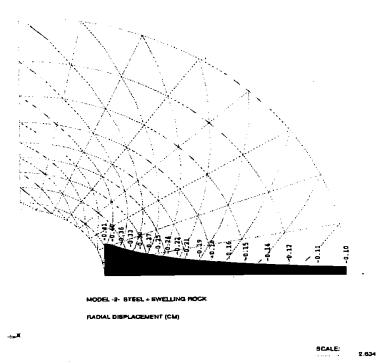

Fig.4 The displacement distribution of the rock in radial direction under swelling pressure( without cement lining) 


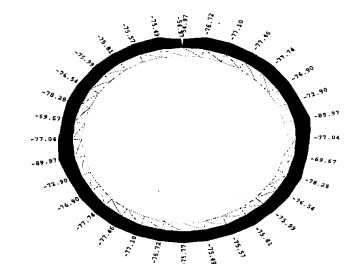

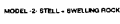

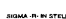

Fig.5 The radial stress distribution of the pipe computed under plane strain condition (without cement lining)

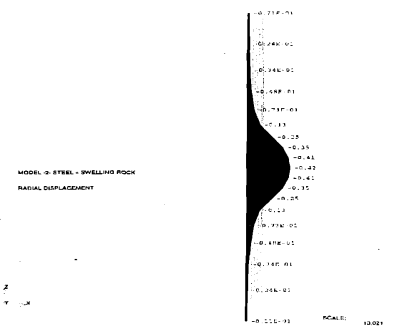

Fig. 7 The radial displacement distribution along the axis of the pipe computed under three-dimensional axisymmetrical condition

( without a cement lining)
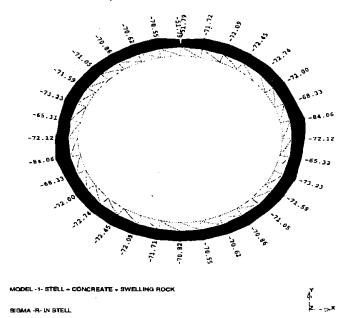

scate: 2.16

Fig. 6 The radial stress distribution of the pipe computed under plane strain condition (with cement lining)



Fig. 8 The radial displacement distribution along the axis of the pipe computed under three-dimensional axisymmetrical condition (without a cement lining) 


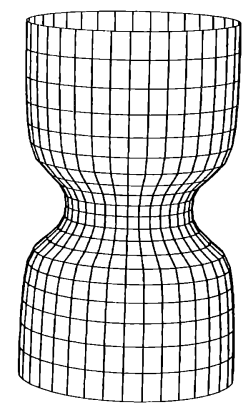

Fig. 9 Necking phenomenon of the casing pipe 